\title{
Abnormal Regulation of Adenosine 3',5'-Monophosphate and Corticosterone Formation in an Adrenocortical Carcinoma
}

\author{
R. L. Ney, N. J. Hochella, D. G. Grahame-Smith, R. N. Dexter, and \\ R. W. BUTCHER \\ From the Department of Medicine, University of North Carolina, Chapel Hill, \\ North Carolina 27514 and the Departments of Medicine and Physiology, \\ Vanderbilt University, Nashville, Tennessee 37203
}

A B S T R A C T A spontaneously occurring rat adrenocortical carcinoma which produces corticosterone was maintained by transplantation. The carcinoma appeared to utilize corticosterone biosynthetic steps similar to those of the normal adrenal, but the tumor produced only about $1-10 \%$ as much corticosterone per unit tissue weight as nontumorous adrenal glands. The tumor demonstrated little or no increase in corticosterone production in response to adrenocorticotropic hormone (ACTH) either in vivo or in vitro.

In normal adrenals, ACTH increases the activity of adenyl cyclase which catalyzes the conversion of adenosine triphosphate (ATP) to adenosine-3', $5^{\prime}$-monophosphate (cyclic AMP), the latter then serving as an intracellular regulator of steroidogenesis. ACTH failed to increase cyclic AMP levels in the tumor in vivo or in slices in vitro, conditions under which there were 50 and 20 -fold increases in nontumorous adrenals. However, in homogenates fortified with exogenous ATP, adenyl cyclase activity was comparable in the tumor and adrenals, and cyclic AMP formation was increased 3-fold by ACTH in each. As measured in homogenates, the tumor did not possess a greater ability to destroy cyclic AMP than did normal adrenals. Although ATP levels in the carcinoma were found to be considerably lower than those in normal adrenals, it was not clear that this finding can explain the inability of $\mathrm{ACTH}$ to increase cyclic AMP levels in intact tumor cells.

While the failure to normally influence cyclic AMP levels in the carcinoma cells could be an important factor in the lack of a steroid response to $\mathrm{ACTH}$, several lines of evidence suggest that the tumor possesses one or more additional abnormalities in the regulation of steroidogenesis. First, in the absence of ACTH stimula-

Dr. Butcher is an Investigator, Howard Hughes Medical Institute.

Received for publication 20 February 1969. tion, the tissue concentrations of cyclic AMP were comparable in the tumor and in nontumorous adrenals, but these cyclic AMP levels were associated with a lower level of steroidogenesis in the tumor. Second, tumor slices failed to increase corticosterone production when incubated with cyclic AMP, in contrast to 5-fold increases observed with nontumorous adrenals.

\section{INTRODUCTION}

It is well known that $\mathrm{ACTH}^{1}$ has little or no stimulatory effect on steroid hormone biosynthesis in many adrenocortical carcinomas (1). The present studies were undertaken to investigate possible factors which might account for this ACTH unresponsiveness. For this purpose, we have utilized a spontaneously occurring, transplantable rat adrenocortical carcinoma that was originally discovered by Snell and Stewart (2). It has been shown previously that this carcinoma produces corticosterone, and that it is capable of utilizing progesterone and deoxycorticosterone as precursors in the formation of corticosterone (3). The present studies provide further evidence that the tumor possesses certain biosynthetic steps leading to the formation of corticosterone that are also found in the normal adrenal cortex, although the activities of the steps are quite different in

\footnotetext{
${ }^{1}$ The following abbreviations and trivial names are employed in the text and tables: cyclic AMP, adenosine- $3^{\prime}, 5^{\prime}-$ monophosphate ; $5^{\prime}$-AMP, adenosine- $5^{\prime}$-monophosphate; ATP, adenosine triphosphate; G6P, glucose-6-phosphate; NADP, nicotinamide adenine dinucleotide phosphate; NADPH, dihydronicotinamide adenine dinucleotide phosphate; cholesterol, $\Delta^{5}$-cholesten-3 $\beta$-ol; $\Delta^{5}$-pregnenolone, $\Delta^{5}$-pregnene- $3 \beta$ ol-20-one; progesterone, $\Delta^{4}$-pregnene-3,20-dione; deoxycorticosterone, 21-hydroxy- $\Delta^{4}$-pregnene-3,20-dione ; corticosterone, $11 \beta, 21$-dihydroxy- $\Delta^{4}$-pregnene-3,20-dione ; cortisol, $11,17,21$ trihydroxy- $\Delta^{4}$-pregnene-3,20-dione; ACTH, adrenocorticotropic hormone; aminoglutethimide, 2-( $p$-aminophenyl) -2ethylglutarimide.
} 
neoplastic and in nontumorous tissues. Furthermore, the activities of the synthetic steps in the tumor were found to be relatively insensitive to the usual stimulatory actions of ACTH.

We have undertaken studies seeking to determine the reasons for the $A C T H$ unresponsiveness of the adrenal carcinoma. In the normal adrenal cortex ACTH increases the activity of adenyl cyclase, which catalyzes the conversion of ATP to cyclic AMP. The cyclic AMP in turn serves as an intracellular mediator of the action of ACTH on steroidogenesis (4-6). Cyclic AMP accelerates the conversion of cholesterol to $\Delta^{5}$-pregnenolone $(\tau)$, which in turn is rapidly converted to corticosterone in the rat adrenal. In an effort to dissect the reasons for the $\mathrm{ACTH}$ unresponsiveness of the rat adrenocortical carcinoma, the following questions were examined: does ACTH normally increase cyclic AMP concentrations in the tumor? And does cyclic AMP in turn accelerate steroidogenesis in the carcinoma as it does in the nontumorous adrenal cortex?

\section{METHODS}

Adrenocortical carcinoma 494 is a spontaneously occurring tumor that was originally discovered in Osborne-Mendel rats by Snell and Stewart (2). The histological features of the tumor have been previously described by these authors (2). We have maintained the tumor by transplantation in both the original strain of Osborne-Mendel rats in which it was discovered and in Sprague-Dawley rats. The growth rate and corticosterone synthetic activity of the tumor has appeared to be similar in these two strains. For transplantation, necrotic portions of the tumor were removed, and the residual tumor was minced into small pieces. The tumor pieces, about $2-3 \mathrm{~mm}$ in diameter, were implanted either intraperitoneally or subcutaneously with a trochar into rats weighing $60-80 \mathrm{~g}$. Approximately $50 \%$ of the rats receiving implants subsequently developed demonstrable tumor masses. In successful transplants, tumor masses of about 2-8 g were present after 4-8 wk. At this time, the tumor was removed and utilized either for retransplantation or for incubation studies.

In vitro studies of steroidogenesis by tumor tissue or adrenal glands were carried out by similar methods. Tumor tissue free of necrosis was sliced and incubated in quantities of $100-250 \mathrm{mg}$ of tissue per flask. Quartered nontumorous adrenal glands from control or tumor-bearing animals were also studied. The incubation medium was Krebs-Ringer bicarbonate buffer containing $200 \mathrm{mg} / 100 \mathrm{ml}$ of glucose. Incubations were carried out in an atmosphere of $95 \% \mathrm{O}_{2}-5 \%$ $\mathrm{CO}_{2}$ at $37^{\circ} \mathrm{C}$ in a water bath with shaking. After a $30 \mathrm{~min}$ period of preincubation in $2 \mathrm{ml}$ of buffer only, the incubation medium was aspirated, and $2 \mathrm{ml}$ fresh medium was added, containing additions as described. The final incubation was then carried out for $2 \mathrm{hr}$. After the incubation, the tissues were homogenized in the $2 \mathrm{ml}$ buffer of the final incubation, and corticosterone was measured in the homogenate. The corticosterone produced by either nontumorous adrenal glands or by the adrenal carcinoma was expressed as $\mu \mathrm{g} / 100$ $\mathrm{mg}$ of tissue per hr of incubation.
Corticosterone was measured in plasma and in adrenal and tumor incubations by the method of Silber, Busch, and Oslapas (8). Cholesterol was assayed in the adrenal carcinoma by the method of Sperry and Webb (9).

Tissue concentrations of cyclic AMP were assayed using methods described previously $(6,10)$. In the in vivo experiments tissues were excised, rapidly weighed, and assayed for their cyclic AMP content. In the in vitro experiments tumor slices or quartered adrenals were weighed and incubated in $2 \mathrm{ml}$ of Krebs-Ringer bicarbonate buffer at $37^{\circ} \mathrm{C}$ for $30 \mathrm{~min}$. At the conclusion of the incubation the tissues were removed and assayed for their cyclic AMP content.

Adenyl cyclase activity in homogenates of normal rat adrenals and of the adrenocortical carcinoma was assayed as described previously (6). Cyclic AMP formation in the presence of added substrate ATP (2 mmoles/liter) served as the index of enzyme activity. Caffeine, an inhibitor of nucleotide phosphodiesterase activity, was added at a concentration of $6.67 \mathrm{mmoles} / \mathrm{liter}$ in order to slow cyclic AMP breakdown. Incubations of the homogenates were carried out at $30^{\circ} \mathrm{C}$ for $15 \mathrm{~min}$ in a water bath with shaking. $1 \mathrm{U}$ of adenyl cyclase activity refers to the production of a micromole of cyclic AMP in $1 \mathrm{~min}$.

Cyclic $3^{\prime}, 5^{\prime}$-nucleotide phosphodiesterase activity, which catalyzes the conversion of cyclic AMP to 5'-AMP, was assayed in homogenates of normal adrenals and tumor tissue according to methods previously described $(11,12) .1 \mathrm{U}$ of enzyme activity refers to the production of $1 \mu$ mole of $5^{\prime}$ AMP from cyclic AMP in $1 \mathrm{~min}$ at $30^{\circ} \mathrm{C}$.

Tissue concentrations of ATP were assayed by the method of Lowry, Passonneau, Hasselberger, and Schultz (13).

\section{RESULTS}

Effects of $A C T H$, cyclic $A M P$, and $N A D P H$ on corticosterone production in the adrenocortical carcinoma and in nontumorous adrenal glands. Initially corticosterone production was evaluated in tumor-bearing animals in vivo both before and after the administration of ACTH. Blood was obtained from the femoral vein for corticosterone assay. Plasma corticosterone was approximately three times normal in the tumor-bearing animals (Table I). 30 min atfer the intravenous injectinon of $1 \mathrm{U}$ of $\mathrm{ACTH}^{2}$ there was a clear increase in plasma corticosterone in control animals, whereas there was no increase in the tumor-bearing animals. Adrenals from the tumor-bearing rats were atrophic, ranging in weight from 13 to $34 \mathrm{mg} /$ adrenal pair in comparison with a range of $38-47 \mathrm{mg}$ in control rats. Pre-

\footnotetext{
${ }^{2}$ Materials were obtained from the following suppliers: zinc ACTH was obtained as Cortrophin-Zinc from Organon Inc., West Orange, N. J.; aminoglutethimide phosphate was obtained from Ciba Pharmaceutical Co., Summit, N. J., and was dissolved in $\mathrm{pH} 4$ acetate buffer before use; cyclic AMP, NADP, and NADPH were otbained from Sigma Chemical Co., St. Louis, Mo.; G6P was obtained from Nutritional Biochemicals Corporation, Cleveland, Ohio; progesterone was obtained from Mann Research Labs Inc., New York; ACTH that was injected intravenously or added to incubations was obtained as a powder from Parke, Davis \& Co., Detroit, Mich., and disolved in Krebs-Ringer bicarbonate buffer just before use.
} 
TABLE I

Peripheral Plasma Corticosterone Concentrations in Control and in Tumor-Bearing Rats before and Again $30 \mathrm{Min}$ after the Intravenous Injection of $1 U$ of $A C T H$

\begin{tabular}{lcc}
\hline \multicolumn{1}{c}{ Treatment } & Controls & Tumor rats \\
\hline & & $\mu g / 100 \mathrm{ml}$ \\
None & $16 \pm 2(4)$ & $44 \pm 11(3)$ \\
ACTH, 1 U, i.v. & $49 \pm 3(4)$ & $38 \pm 5(3)$ \\
\hline
\end{tabular}

The number of animals is shown in parentheses. All values are expressed as mean \pm SEM.

ACTH, adrenocorticotropic hormone.

sumably the quantity of corticosterone secreted by the adrenal carcinoma was sufficient to cause elevated plasma level of corticosterone and thereby to suppress pituitary ACTH release with resultant adrenal atrophy. The lack of response of the tumor-bearing animals to the injection of ACTH can be explained by a combination of atrophic nontumorous adrenals incapable of an immediate response to ACTH and tumor tissue which fails to demonstrate a measurable in vivo response.

In order to compare corticosterone synthesis in the adrenocortical carcinoma with that in nontumorous adrenal glands, the tissues were studied separately in vitro. The data for the adrenal glands are shown in Table II, and the results for the adrenocortical carcinoma are shown in Table III. In comparison with adrenals from control animals, the atrophic adrenals from tumorbearing rats demonstrated only a small increase in corticosterone production when incubated with either ACTH or with cyclic AMP. Since NADPH is known to stimulate adrenal steroidogenesis (14), the response of the adrenals to an NADPH-generating system (NADP + G6P) was also tested. Once again, the atrophic adrenals from tumor-bearing animals demonstrated only small responses in comparison with the controls. These limited
TABLE III

In Vitro Corticosterone Production by the Adrenocortical Carcinoma from Rats That Either Received No Pretreatment or Received Zinc ACTH, 2.5 U Subcutaneously Twice Daily for 3 Days

\begin{tabular}{lcc}
\hline \multicolumn{1}{c}{$\begin{array}{c}\text { Additions to } \\
\text { incubations }\end{array}$} & No pretreatment & $\begin{array}{c}\text { Zinc ACTH pre- } \\
\text { treatment }\end{array}$ \\
\hline & \multicolumn{2}{c}{$\mu g / 100 \mathrm{mg}$ tissue $/ \mathrm{hr}$} \\
None & $0.20 \pm 0.02(21)$ & $0.17 \pm 0.02(9)$ \\
$\mathrm{ACTH}, 2.5 \mathrm{U} / \mathrm{ml}$ & $0.31 \pm 0.04(25)$ & $0.27 \pm 0.04(18)$ \\
$10 \mathrm{mM}$ cyclic AMP & $0.27 \pm 0.03(13)$ & $0.15 \pm 0.02(13)$ \\
$1 \mathrm{mM} \mathrm{NADP}$ & & \\
$\quad+2.5 \mathrm{mM} \mathrm{G6P}$ & $0.31 \pm 0.07(4)$ & $0.38 \pm 0.14(2)$ \\
$0.5 \mathrm{mM} \mathrm{NADPH}$ & $0.29 \pm 0.01(2)$ & $0.30 \pm 0.08(2)$ \\
\hline
\end{tabular}

The number of observations is shown in parentheses. All values are expressed as mean \pm SEM.

NADPH, dihydronicotinamide adenine dinucleotide phosphate.

responses of the atrophic adrenals from tumor-bearing animals may well have been due to chronic suppression of ACTH production by tumor corticosterone. In accordance with this interpretation, when tumor-bearing animals were pretreated with zinc ACTH, $2.5 \mathrm{U}$ subcutaneously twice daily for 3 days, the nontumorous adrenals from these animals were increased in size (range 39-71 mg/adrenal pair) and demonstrated markedly enhanced in vitro responses to ACTH, cyclic AMP, and the NADPH-generating system (Table II).

During incubation, the carcinoma was less active than the nontumorous adrenals in corticosterone production per unit of tissue weight, the tumor values ranging from approximately 1 to $10 \%$ of the adrenal values. In line with this finding, tumor-bearing animals possessed large tumor masses when their plasma levels of corticosterone were elevated. The content of preformed corticosterone in the carcinoma at the time of excision of the tissue

TABLE II

In Vitro Corticosterone Production by Nontumorous Adrenals from Tumor-Bearing Rats and by Adrenals from Control Rats without Tumor Transplants

\begin{tabular}{|c|c|c|c|}
\hline \multirow[b]{2}{*}{ Additions to incubations } & \multirow[b]{2}{*}{ Controls } & \multicolumn{2}{|c|}{ Tumor-bearing rats } \\
\hline & & No pretreatment & Zinc ACTH pretreatment \\
\hline & & \multicolumn{2}{|c|}{$\mu g / 100 \mathrm{mg}$ tissue $/ \mathrm{hr}$} \\
\hline None & $3.9 \pm 0.7(12)$ & $2.3 \pm 0.5(10)$ & $5.4 \pm 1.9(5)$ \\
\hline $\mathrm{ACTH}, 2.5 \mathrm{U} / \mathrm{ml}$ & $14.9 \pm 2.3(6)$ & $6.2 \pm 1.3(8)$ & $33.3 \pm 4.0(5)$ \\
\hline 10mM cyclic AMP & $22.2 \pm 2.9(9)$ & $5.1 \pm 3.9(4)$ & $27.6 \pm 5.2(4)$ \\
\hline $1 \mathrm{~mm}$ NADP $+2.5 \mathrm{~mm}$ G6P & $27.4 \pm 4.2(4)$ & $8.3 \pm 4.2(6)$ & $15.8 \pm 0.3(2)$ \\
\hline
\end{tabular}

As indicated by the column headings, some of the tumor-bearing rats received no pretreatment, while other received zinc ACTH $2.5 \mathrm{U}$ twice daily subcutaneously for 3 days. The number of observations in each group is indicated in parentheses. All values expressed as mean \pm SEM.

Cyclic AMP, adenosine-3', 5'-monophosphate; NADP, nicotinamide adenine dinucleatide phosphate; G6P, glucose-6-phosphate. 
before incubation was $0.06 \pm 0.02$ (SE) $\mu \mathrm{g} / 100 \mathrm{mg}$ of tissue (10 transplants) for tumors from untreated rats, and was $0.06 \pm 0.02$ ( 7 transplants) for tumors from zinc ACTH-treated rats. The carcinoma produced corticosterone during the incubations but demonstrated only small increases in corticosterone production when incubated with ACTH, cyclic AMP, an NADPH-generating system, or NADPH itself (Table III). The small responses of the carcinoma to the various additions were not increased when the animals were pretreated with zinc ACTH (Table III), in marked contrast to the findings with the nontumorous adrenals from these same animals (Table II). Thus, while the limited responses of the atrophic nontumorous adrenals could be ascribed to chronic ACTH suppression, this same reasoning could not explain the limited responses of the carcinoma.

Studies of the corticosterone biosynthetic pathrway in the adrenocortical carcinoma. One possible explanation for the ACTH insensitivity of the adrenal carcinoma was that the tumor by-passed ACTH-sensitive steps in the biosynthesis of corticosterone. Alternatively, the corticosterone biosynthetic sequences might have been qualitatively similar in the carcinoma and in the normal adrenal, but the tumor possessed other defects which limited the action of ACTH. In the normal rat adrenal, cholesterol is converted through a series of reactions to $\Delta^{5}$-pregnenolone. It is this conversion that is stimulated by ACTH in its action to accelerate steroidogenesis (7). Subsequent reactions lead sequentially from $\Delta^{5}$ pregnenolone to progesterone, deoxycorticosterone, and finally corticosterone (15).

The adrenal carcinoma was found to contain cholesterol in a concentartion of $0.21 \pm 0.01 \mathrm{mg} / 100 \mathrm{mg}$ of tissue (mean \pm SEM, four animals), a value similar to that reported by Lossow, Shyamala, Shah, and Chaikoff for this tumor (16) but considerably less than that observed in normal adrenals (17). Aminoglutethimide has been shown to inhibit the conversion of cholesterol to $\Delta^{5}$ pregnenolone, thereby diminishing corticosterone production by the normal adrenal (18). Tumor-bearing

\begin{tabular}{lc}
\multicolumn{2}{c}{ TABLE IV } \\
\multicolumn{2}{c}{$\begin{array}{c}\text { In Vitro Corticosterone Production by } \\
\text { Adrenocortical Tumor Slices }\end{array}$} \\
\hline \multicolumn{2}{c}{ Additions to incubations } \\
\hline \\
None & $\mu \mathrm{g} / 100 \mathrm{mg}$ tissue $/ \mathrm{hr}$ \\
$\Delta^{5}$-pregnenolone, $50 \mu \mathrm{g} / \mathrm{ml}$ & $0.20 \pm 0.02(21)$ \\
Progesterone, $50 \mu \mathrm{g} / \mathrm{ml}$ & $1.02 \pm 0.25(3)$ \\
$0.76 \mathrm{~mm}$ aminoglutethimide & $1.19 \pm 0.23(10)$ \\
\end{tabular}

The number of observations is shown in parentheses. The data for incubations without additions are also shown in Table III. All values are expressed as mean \pm SEM.
TABLE $\mathrm{V}$

In Vivo Cyclic AMP Concentrations in Tumor-Bearing Rats

\begin{tabular}{ccc}
\hline $\begin{array}{c}\text { Treatment of } \\
\text { tumor-bearing } \\
\text { animal }\end{array}$ & $\begin{array}{c}\text { Nontumorous } \\
\text { adrenal glands }\end{array}$ & Adrenal tumor \\
\hline \multicolumn{2}{c}{ nmoles/gtissue } \\
None & $2.3 \pm 0.6(3)$ & $4.0 \pm 0.6(5)$ \\
ACTH & $123.7 \pm 22.8(6)$ & $6.6 \pm 2.1(8)$ \\
\hline
\end{tabular}

Adrenal tumor and nontumorous adrenals were assayed without ACTH treatment, and about $5 \mathrm{~min}$ after the injection of $20 \mathrm{U}$ of ACTH in the femoral vein. The number of observations is in parentheses. All values are expressed as mean $\pm \mathrm{SEM}$.

rats were treated with $20 \mathrm{mg}$ of aminoglutethimide phosphate subcutaneously twice daily for 3 days. At the end of this time, plasma corticosterone was $15 \pm 1 \mu \mathrm{g} / 100 \mathrm{ml}$ (two animals), a decrease from the values observed in untreated tumor-bearing animals (Table I). In addition, corticosterone production was inhibited when the carcinoma was incubated with aminoglutethimide (Table IV). Although it is recognized that aminoglutethimide may have different effects in the carcinoma than in normal adrenals, the experiments do at least suggest that the conversion of cholesterol to $\Delta^{5}$-pregnenolone lies in the pathway of corticosterone synthesis in the carcinoma. When the conversion of cholesterol to $\Delta^{5}$-pregnenolone is inhibited by aminoglutethimide, then corticosterone production is accordingly decreased. Similarly, Schteingart, Cash, and Conn found that aminoglutethimide inhibited cortisol production by a human adrenocortical carcinoma (19).

In the normal adrenal, once $\Delta^{5}$-pregnenolone is formed under the influence of ACTH it is readily converted to corticosterone through a series of steps involving progesterone and deoxycorticosterone as intermediates. Accordingly, when adrenals are incubated with exoge-

\section{TABLE VI}

In Vitro Cyclic AMP Concentrations in Quartered Nontumorous Rat Adrenal Glands and in Slices of the Adrenocortical Carcinoma

\begin{tabular}{|c|c|c|}
\hline Additions & $\begin{array}{l}\text { Normal adrenal } \\
\text { glands }\end{array}$ & Adrenal tumor \\
\hline & \multicolumn{2}{|c|}{ nmoles/g tissue } \\
\hline None & $0.7 \pm 0.1$ & $1.1 \pm 0.1$ \\
\hline ACTH, $1 \mathrm{U} / \mathrm{ml}$ & $16.2 \pm 1.1(8)$ & $1.6 \pm 0.3(6)$ \\
\hline
\end{tabular}

The tissues were incubated for $30 \mathrm{~min}$. At the end of this period, the tissues were removed from the incubation medium and assayed for cyclic AMP. The number of observations is indicated in parentheses. The data for the normal adrenals have been reported previously (6). All values are expressed as mean \pm SEM. 
nous $\Delta^{5}$-pregnenolone, progesterone, or deoxycorticosterone, the formation of corticosterone is increased (20). To test whether the adrenocortical carcinoma could also perform this series of reactions, tumor tissue was incubated with exogenous $\Delta^{5}$-pregnenolone or progesterone, and it was found that corticosterone production was enhanced (Table IV). Previous studies have shown the conversion of tracer quantities of isotopically labeled progesterone and deoxycorticosterone to corticosterone by this tumor (3). It would therefore appear that the tumor possesses the capacity to carry out certain reactions in corticosterone biosynthesis that are found in the normal adrenal.

Cyclic AMP concentrations in the adrenocortical carcinoma and in nontumorous adrenals. Studies were performed to determine whether the failure of ACTH to increase corticosterone biosynthesis in the carcinoma might be due to a failure to increase tissue cyclic AMP concentrations. When the carcinoma and nontumorous adrenals were removed from tumor-bearing animals, the concentrations of cyclic AMP in the two tissues were not greatly different (Table V). When the tumor-bearing animals were injected with $20 \mathrm{U}$ of ACTH in the femoral vein and the tissues excised $5 \mathrm{~min}$ later, there was only a small increase in cyclic AMP levels in the tumor but a 50-fold increase in the cyclic AMP levels in nontumorous adrenals of these same animals.

When tumor slices and quartered adrenals were incubated for $30 \mathrm{~min}$ in vitro in the absence of ACTH, concentrations of cyclic AMP in the two tissues were comparable. When ACTH, $1 \mathrm{U} / \mathrm{ml}$, was present in the incubation medium there was a 20 -fold increase in cyclic AMP levels in the adrenals but little change in the tumor (Table VI).

Phosphodiesterase activity in the tumor and in nontumorous adrenals. One possible explanation for the inability of ACTH to increase tumor cyclic AMP levels would be a rapid rate of degradation of the cyclic nucleotide. This degradation is accomplished at least partly by the enzyme cyclic nucleotide phosphodiesterase which catalyzes the conversion of cyclic AMP to $5^{\prime}$-AMP (11, 12). The possible participation of other pathways of cyclic AMP metabolism has not been excluded. Phos-

\section{TABLE VII}

Phosphodiesterase Activity in Nontumorous Adrenal Glands and in the Adrenocortical Carcinoma

\begin{tabular}{cc}
\hline Tissue & $\begin{array}{c}\text { Cyclic } 3^{\prime}, 5^{\prime} \text {-nucleotide phospho- } \\
\text { diesterase activity }\end{array}$ \\
& $U / g$ wet tissue weight \\
Adrenals & $1.45 \pm 0.05(4)$ \\
Tumor & $0.38 \pm 0.14(2)$ \\
\hline
\end{tabular}

All values are expressed as mean \pm SEM. phodiesterase activity was assayed and found to be lower in homogenates of the adrenocortical carcinoma than in homogenates of normal adrenals (Table VII).

In an additional experiment, tumor slices were incubated with $10 \mathrm{~mm}$ caffeine for $30 \mathrm{~min}$. Caffeine inhibits phosphodiesterase activity, and it was considered possible that a stimulatory effect of $\mathrm{ACTH}$ on cyclic AMP formation might be uncovered under these conditions. When tumor slices were incubated with caffeine alone, the tissue concentration of cyclic AMP was 6.05 nmoles/ $\mathrm{g}$, a value somewhat higher than that observed when the tumor was incubated under identical conditions but without caffeine (Table VI). When incubated with ACTH, $1 \mathrm{U} / \mathrm{ml}$ in addition to caffeine, the tumor concentration of cyclic AMP was 6.75 nmoles $/ \mathrm{g}$ of tissue. Thus, although caffeine itself increased the level of cyclic AMP in tumor tissue above that ordinarily seen, a stimulatory effect of ACTH on cyclic AMP accumulation was still not observed.

The studies suggest that while $\mathrm{ACTH}$ failed to increase cyclic AMP concentrations in the tumor in vivo and in tumor slices in vitro, this defect cannot be attributed to rapid degradation of cyclic AMP by phosphodiesterase.

Adenyl cyclase activity in homogenates of the adrenal tumor and of nontumorous adrenals. In addition to assaying cyclic AMP concentrations in intact cell preparations (in vivo experiments and in vitro experiments with tissue slices), broken cell preparations were used for the assay of adenyl cyclase activity. Cyclic AMP formation in homogenates to which substrate ATP had been added (in a final concentration of 2 mmoles/liter) was used as an index of adenyl cyclase activity (6). Caffeine (6.67 mmoles/liter) was also added to hinder cyclic AMP breakdown. Adenyl cyclase activity was not greatly different in homogenates of the tumor and of normal adrenals (Table VIII). In light of the failure of ACTH to normally increase cyclic AMP levels in intact tumor cells, it was surprising that ACTH produced increases in adenyl cyclase activity in tumor homogenates that were, if anything, greater than those observed in adrenal homogenates. Sodium fluoride also

TABLE VIII

Effects of ACTH and Sodium Fluoride ( $\mathrm{NaF}$ ) on Adenyl Cyclase Activity in Homogenates of Normal Adrenals and of the Adrenocortical Carcinoma

\begin{tabular}{lrc}
\hline \multicolumn{1}{c}{ Additions } & \multicolumn{1}{c}{ Adrenal } & Tumor \\
\hline & \multicolumn{3}{c}{$m U / g$ tissue } \\
Control & $1.3 \pm 0.3(5)$ & $1.8 \pm 0.4(6)$ \\
ACTH, 0.66 U/ml & $3.0 \pm 0.7(5)$ & $6.0 \pm 0.9(6)$ \\
NaF, 0.01 moles/liter & $12.4 \pm 1.2(5)$ & $5.6 \pm 1.1(6)$ \\
\hline
\end{tabular}

The number of experiments is shown in parentheses. All values are expressed as mean \pm SEM.

Cyclic AMP in an Adrenocortical Carcinoma 
TABLE IX

Concentrations of ATP in Normal Adrenals and in the Adrenocortical Carcinoma

\begin{tabular}{lcc}
\hline $\begin{array}{c}\text { Treat- } \\
\text { ment }\end{array}$ & Adrenals & Tumor \\
\hline \multirow{2}{*}{ None } & \multicolumn{2}{c}{ mmoles $/$ kg wet weight } \\
& $0.73 \pm 0.09$ & $0.38 \pm 0.07$ \\
ACTH & $(13)$ & $(13)$ \\
& $0.76 \pm 0.11$ & $0.38 \pm 0.11$ \\
& $(7)$ & $(6)$
\end{tabular}

The numbers in parentheses indicate the number of tumor specimens or paired adrenals that were studied. Some of the animals received ACTH, $5 \mathrm{U}$ intravenously, $5 \mathrm{~min}$ before removal of the tissues for assay.

stimulated the activity in the tumor homogenates, although to a lesser degree than in the adrenal homogenates.

ATP concentrations in the adrenal carcinoma and in normal adrenals. A possible factor that could have limited the ability of ACTH to increase cyclic AMP levels in the carcinoma cells was insufficiency of substrate ATP, a defect that would have been overcome in the adenyl cyclase assays in homogenates which were fortified with added ATP. Tumor concentrations of ATP were about one-half those of normal adrenals (Table IX), a significant difference $(P<0.01)$. The intravenous injection of $5 \mathrm{U}$ of ACTH $5 \mathrm{~min}$ before the excision of the tissues did not modify the ATP levels in either the adrenals or the tumor.

\section{DISCUSSION}

The present studies with a rat adrenocortical carcinoma suggest that the tumor is capable of utilizing certain corticosterone biosynthetic sequences known to be present in the normal rat adrenal. Thus, the tumor appears to utilize cholesterol, at least in part, as a precursor for corticosterone, and is capable of converting exogenous $\Delta^{5}$-pregnenolone and progesterone to corticosterone. It should be noted, however, that these studies have not examined all of the intermediates nor all of the reactions involved in the process of corticosterone synthesis. Therefore, differences in the pathway in the tumor and in the normal adrenal cannot be completely excluded at present. It is clear that the tumor tissue is much less active than normal adrenals in corticosterone synthesis, and previous studies have shown reduction in the rate of $11 \beta$-hydroxylation of deoxycorticosterone to corticosterone in the tumor (3). Furthermore, ACTH did not increase the rate of corticosterone production by the carcinoma in vivo or in vitro.

Additional studies examined possible reasons for the $\mathrm{ACTH}$ insensitivity of the tumor. ACTH produced little or no increase in cyclic AMP concentrations in the tumor in vivo and in slices in vitro in contrast to marked increases produced in nontumorous adrenals. This result did not appear to be due to rapid cyclic AMP degradation by tumor cyclic nucleotide phosphodiesterase. In contrast to the failure of ACTH to increase cyclic AMP levels in intact tumor cells in vivo or in vitro, ACTH increased adenyl cyclase activity in tumor homogenates that were fortified with exogenous ATP. The tumor was found to possess decreased ATP concentrations when compared with normal adrenals. For several reasons, however, it is uncertain whether this represented a limiting factor in the capability of intact tumor cells to increase cyclic AMP levels in response to ACTH. The substrate ATP requirements of adenyl cyclase are not clearly defined in either adrenals or tumor, and little is known concerning the accessibility of ATP to the enzyme in organized adrenal and tumor cells. It is of interest, however, that when adenyl cyclase activity was examined in rat liver particles, reduction in ATP concentrations from 2 to 0.5 mmoles/liter resulted in marked diminution in the formation of cyclic AMP (21). The reason for the decreased ATP concentrations in the tumor remains to be clarified. It also remains to be established whether other factors are important in the failure of ACTH to increase cyclic AMP levels in intact tumor cells. For example, the presence of inhibitors of adenyl cyclase activity or an abnormal subcellular distribution of the enzyme making it inaccessible to ACTH could be important factors.

It is clear that the failure of $\mathrm{ACTH}$ to increase tumor cyclic AMP concentrations could impose an important limitation on the stimulation of steroidogenesis in this tissue. Several lines of evidence, however, suggest that the tumor possesses additional abnormalities in the regulation of steroidogenesis. First, base line concentrations of cyclic AMP (in the absence of added ACTH) were similar in the carcinoma and in adrenals (Tables $\mathrm{V}$, VI). However, this same level of tissue cyclic AMP was associated with a much lower level of steroidogenesis in the tumor than in adrenals (Tables II, III). Furthermore, when tumor slices were incubated with added cyclic AMP, there was little increase in corticosterone production (Table III) in contrast to the marked increase observed with nontumorous adrenals (Table II). One possibility that cannot be excluded from the present studies is that the tumor is composed of a heterogeneous cell population. Although marked heterogeneity is not evident from histological observations (2), it is possible that the cells are heterogeneous in function. Thus only a small percentage of the cell population might be active in steroid production, and these cells might be functioning at a maximal rate rendering them insensitive to further stimulation. 


\section{ACKNOWLEDGMENTS}

Dr. Katherine C. Snell of the National Cancer Institute generously provided the rat adrenocortical carcinoma. Mrs. C. Baird and Mrs. B. Watson assisted invaluably in the performance of the studies.

This work was supported by grants CA-10408 and HE08332 from the National Institutes of Health, U. S. Public Health Service.

\section{REFERENCES}

1. Lipsett, M. B., R. Hertz, and G. T. Ross. 1963. Clinical and pathophysiologic aspects of adrenocortical carcinoma. Amer. J. Med. $35: 374$.

2. Snell, K. C., and H. L. Stewart, 1959. Variations in histological pattern and functional effects of a transplantable adrenal cortical carcinoma in intact, hypophysectomized and newborn rats. J. Nat. Cancer Inst. 22: 1119.

3. Johnson, D. F., K. C. Snell, D. Francois, and E. Heftmann. 1961. In vitro metabolism of progesterone-4- ${ }^{14} \mathrm{C}$ in an adrenocortical carcinoma of the rat. Acta Endocrinol. $37: 329$.

4. Haynes, R. C., Jr. 1958. The activation of adrenal phosphorylase by the adrenocorticotropic hormone. J. Biol. Chem. 233: 1220.

5. Haynes, R. C., Jr., S. B. Koritz, and F. G. Péron. 1959. Influence of adenosine- $3^{\prime}, 5^{\prime}$-monophosphate on corticoid production by rat adrenal glands. J. Biol. Chem. 234: 1421.

6. Grahame-Smith, D. G., R. W. Butcher, R. L. Ney, and E. W. Sutherland. 1967. Adenosine- $3^{\prime}, 5^{\prime}$-phosphate as the intracellular mediator of the action of adrenocorticotropic hormone on the adrenal cortex. J. Biol. Chem. 242: 5535.

7. Karaboyas, G. C., and S. B. Koritz. 1965. Identity of the site of action of $3^{\prime}, 5^{\prime}$-adenosine monophosphate and adrenocorticotropic hormone in corticosteroidogenesis in rat adrenal and beef adrenal cortex slices. Biochemistry. 4: 462 .

8. Silber, R. H., R. D. Busch, and R. Oslapas. 1958. Practical procedure for estimation of corticosterone or hydrocortisone. Clin. Chem. 4: 278.

9. Sperry, W. M., and M. Webb. 1950. A revision of the Schoenheimer-Sperry method for cholesterol determination. J. Biol. Chem. 187: 97.
10. Butcher, R. W., R. J. Ho, H. C. Meng, and E. W. Sutherland. 1965. Adenosine- $3^{\prime}, 5^{\prime}$-monophosphate in biological materials. II. The measurement of adenosine $3^{\prime}, 5^{\prime}$-monophosphate in tissues and the role of cyclic nucleotide in the lipolytic response of fat to epinephrine. J. Biol. Chem. 240: 4515.

11. Butcher, R. W., and E. W. Sutherland. 1962. Adenosine$3^{\prime}, 5^{\prime}$-phosphate in biological materials. I. Purification and properties of cyclic $3^{\prime}, 5^{\prime}$-nucleotide phosphodiesterase and use of this enzyme to characterize adenosine $3^{\prime}, 5^{\prime}$-phosphate in human urine. J. Biol. Chem. 237: 1244.

12. DeRobertis, E. D., G. R. De Lores Arnaz, M. A1berici, R. W. Butcher, and E. W. Sutherland. 1967. Subcellular distribution of adenyl cyclase and cyclic phosphodiesterase in rat brain cortex. J. Biol. Chem. 242: 3487.

13. Lowry, O. H., J. V. Passonneau, F. X. Hasselberger, and D. W. Schultz. 1964. Effect of ischemia on known substrates and cofactors of the glycolytic pathway in brain. J. Biol. Chem. 239: 18.

14. Koritz, S. B., and F. G. Péron. 1958. Studies on mode of action of adrenocorticotropic hormone. J. Biol. Chem. 230: 343

15. Vinson, G. P. 1966. Pathways of corticosteroid biosynthesis from pregnenolone and progesterone in rat adrenal glands. J. Endocrinol. 34: 355.

16. Lossow, W. J., G. Shyamala, S. Shah, and L. L. Chaikoff. 1965. Uptake, hydrolysis and synthesis of cholesterol esters by a transplantable adrenal cortical tumor. Proc. Soc. Exp. Biol. Med. 119: 126.

17. Long, C. N. H. 1947. The relation of cholesterol and ascorbic acid to the secretion of the adrenal cortex. Recent Progr. Hormone Res. 1: 99.

18. Dexter, R. N., L. M. Fishman, R. L. Ney, and G. W. Liddle. 1967. Inhibition of adrenal corticosteroid synthesis by amino-glutethimide: studies on the mechanism of action. J. Clin. Endocrinol. Metab. 27: 473.

19. Schteingart, D. E., R. Cash, and J. W. Conn. 1966. Aminoglutethimide and metastatic adrenal cancer. $J$. Amer. Med. Ass. 198: 1007.

20. Ney, R. L., R. N. Dexter, W. W. Davis, and L. D. Garren. 1967. A study of the mechanisms by which adrenocorticotropic hormone maintains adrenal steroidogenic responsiveness. J. Clin. Invest. 46: 1916.

21. Rall, T. W., and E. W. Sutherland. 1958. Formation of a cyclic adenine ribonucleotide by tissue particles. $J$. Biol. Chem. 232: 1065. 